Bangladesh J. Sci. Ind. Res. 42(4), 483-488, 2007

\title{
Microbial Antagonism and Induction of Mutation in Neurospora Crassa by Crude Leaves Extract of Averrhoa carambola.L.
}

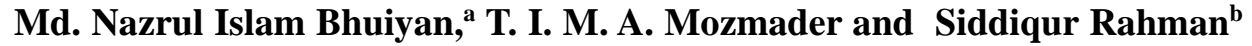 \\ ${ }^{a}$ BCSIR Laboratories, Chittagong-4220 and ${ }^{b}$ Department of Botany, \\ University of Dhaka,Dhaka-1000,Bangladesh.
}

\begin{abstract}
Crude extract of leaves from Averrhoa carambola .L showed significant inhibition of growth and mutagenesis in Neurospora crassa. Result showed that $1 \mathrm{ml}$ extract reacted with the test organism, $N$. crassa very much. During the period of 24 hours it gave only $2.4 \mathrm{~cm}$ linear vegetative growth of the mycelia. Whereas $0.5 \mathrm{ml}$ and $0.25 \mathrm{ml}$ extracts gave less reactions $(1.75 \mathrm{~cm}$ and $2.25 \mathrm{~cm}$ respectively). The linear growth decreased with the increased of the concentration of the extracts. Conidia of Ema (5297) of $N$. crassa were treated for 3-4 hours separately in $100 \%$ and $50 \%$ concentration of the extracts. $100 \%$ extracts produced 4 types mutants namely ropy, albino, dirty and buff. 50\% extracts produced 4 types of mutants namely- plug, vigorous, pigmented and conidial band.
\end{abstract}

Key words: Neurospora crassa, Averrhoa carambola, mutants, ropy, albino, dirty,buff, plug, vigorous, pigmented and conidial band.

\section{Introduction}

Beadle and Tatum (1941) first used the $N$. crassa in genetically and at the same time for biochemical study. $N$. crassa was originally selected for studying biochemical genetics because it is an organism in, which both formal genetic analysis and investigation of nutritional mutants appeared possible.

Mutagens are physical or chemical agents such as radiation, heat or alkalizing or determinations agents, which raise the frequency of mutation, greatly above the spontaneous background level. Chemical mutagens have the ability to penetrate cells and to alter the DNA within cell (Fishbein et. al., 1970), Chemicals that have mutagenic properties include peroxides, formaldehyde (Gardner, 1972), Permanganate, urethane, nitrous acid, Ethyl Methyl Sulphonate (EMS), Mustard gas (Altenberg, 1957), Chloramphenicol etc. 
In 1939, Steinberg first reported the production of mutation by chemical treatment of cells. Study of Kolmarks and Westergaard (1949) have shown that Bromoethyl methane sulphonate when used on $N$. crassa causes mutation. Admirable accounts both of genetical and much of biochemical work is given by Cateheside (1949) and Horowitz (1973) . Perhaps Westergaard has made the most extensive and systemic surveys of the action of biochemical mutagens on fungi on $N$. crassa (Fincham and Day, 1965).

Mutation is the ultimate source of all genetic variation and it provides the raw material for evolution, Mutation provide decisive evidence that DNA is the genetic material. Artificial induction of mutation is one of the criteria to study the organization and mode of action of genes. Now a days a good number of physical and chemical mutagens are used by the geneticists for induction of mutation. Chemical mutagens have the ability to penetrate cells and to alter the DNA. Presently scientist are interested to evaluate the mutagenic properties of chemicals on Neurospora crassa. The experimental material $N$. crassa is a well-known pink bread mold. It is a filamentous fungus that belongs to the class-Ascomycetes. Plant extracts play an important role to check the growth of various fungi. Scientists are interested in evaluating the antifungal activities of plant extracts against plant pathogenic fungi (Ahmed and Sultana, 1984; Miah et. al., 1990; Bashar and Rai, 1991; Anwar et. al.,
1994 .). Haque and Shamsi (1996) observed that leaf extracts of neem (Azadirachta indi$\mathrm{ca}$ ) has antifungal properties and it decreased the radial growth of fungus but none of them studied the mutagenic effect of the plant extracts. The most technically advantageous method of studying the organization and mode of action of gene or the genie inheritance in any organism is achieved by inducing artificial mutation in the organism at different loci. Without mutation the loci could never be identified; nor their functions studied. The present study was undertaken to find the microbial antagonism and mutagenic effect of leaf extracts of $A$. carambola on $N$. crassa \& thereby to produce mutation in $N$. crassa. A. carambola. $\mathrm{L}$ is a wellknown medicinal plant (FamilyAverrhoaceae).

\section{Materials and Methods}

$N$. crassa Ema (5297) was the experimental material. The wild type strain was received from Fungal Genetic Stock Centre, Department of Microbiology, University of Kansas Medical School, Kansas, U.S.A. Strains Ema (5297) were used. Vogel's minimal medium (VM) (Vogel, 1956) was used for the maintenance of cultures. Solid VM was used for obtaining and measuring linear growth of conidia (Ryan et. al., 1943). Different concentration of aqueous extracts of leaves of $A$. carambola $\mathrm{L}$. were used in the experiments, The extraction procedure are given below: 
Aqueous extract: Mature fresh green leaves of $A$. carambola L. was washed with sterilized distilled water and then air dried.100 g of clean leaves was grinned with mortar and paste. The paste was filtered through extracts. The filtered extract was centrifuged for 5 minutes in $300 \mathrm{rpm}$ at $25^{\circ} \mathrm{C}$. The supernatant was used for this experiment.

Conidia of Ema (5297) of $N$. crassa were treated for 3-4 hours separately in 100\% and $50 \%$ concentration of the extracts. It was centrifuged and the supernatant was discarded, treated conidia were washed twice with sterilized distilled water by pouring $1 \mathrm{ml}$ sterilized distilled in each centrifuge tube.
Final suspension was made with sterilized distilled water. One drop (about 10,000 $\mu \mathrm{l}$ inocula) of conidial suspension was taken in each of the 40 Petri dishes. Molten Sorbose minimal medium (SM) was poured in each to the 40 Petri dishes for mycelial linear growth. Plates were incubated at $25^{\mathrm{O}} \mathrm{C}$ for formation of conidial colonies for 3 days. Observation was taken each day for appearance of colony. The colonies were isolated in the test tubes containing Vogel's minimal medium (VM). Incubated the isolates for growth at $25^{\circ} \mathrm{C}$. After 4 days the isolates were examined and classified.

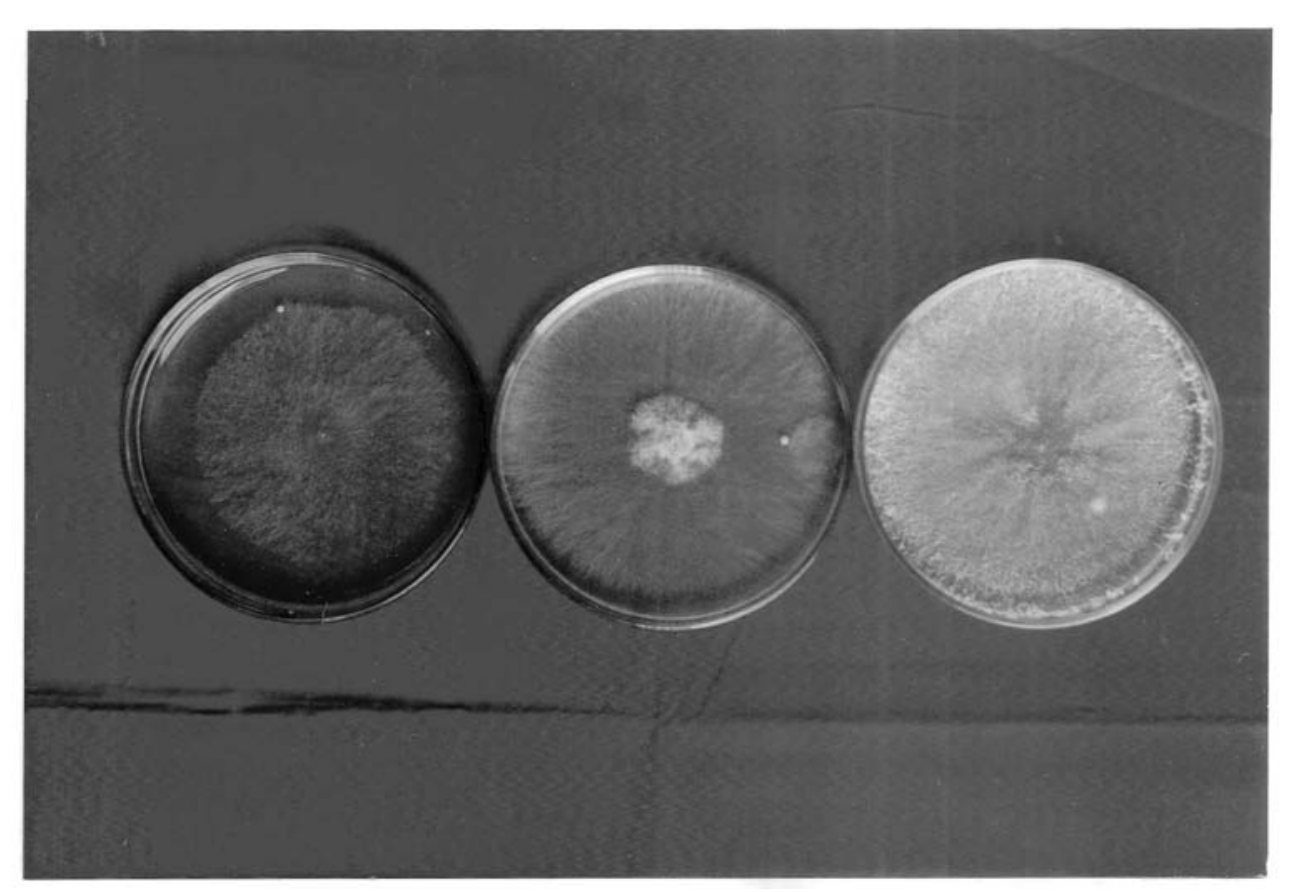

Fig. 1. Comparative studies of linear growth in different concentrations $(0.25 \mathrm{ml}, 0.50 \mathrm{ml}$ and $1 \mathrm{ml}$ concentrations respectively) 


\section{Results and Discussion}

Crude extracts of leaves from A. carambola .L. showed significant inhibition of growth and mutagenesis $N$. crassa. Result showed that $1 \mathrm{ml}$ extract reacted with the test organism, $N$. crassa very much. During the period of 24 hours it gave only $2.4 \mathrm{~cm}$ linear vegetative growth of the mycelia. Whereas $0.5 \mathrm{ml}$ and $0.25 \mathrm{ml}$ extracts gave less reactions $(1.75 \mathrm{~cm}$ and $2.25 \mathrm{~cm}$ respectively). (Fig.1) The linear growth decreased with the increase of the concentration of the extracts.
Crude extracts of leaves from A. carambola L. Showed mutagenesis with the test organism, N. crassa. Conidia of Ema (5297) of N. crassa were treated for 3-4 hours separately in $100 \%$ and $50 \%$ concentration of the extracts. One hundred percent extracts produced four types of mutants, namely- dirty, ropy, albino, and buff and 50\% extracts produced four types of mutants, namely- plug, vigorous, pigmented and conidial band. So total mutants 8 types ( Fig. 2 and Table.I).

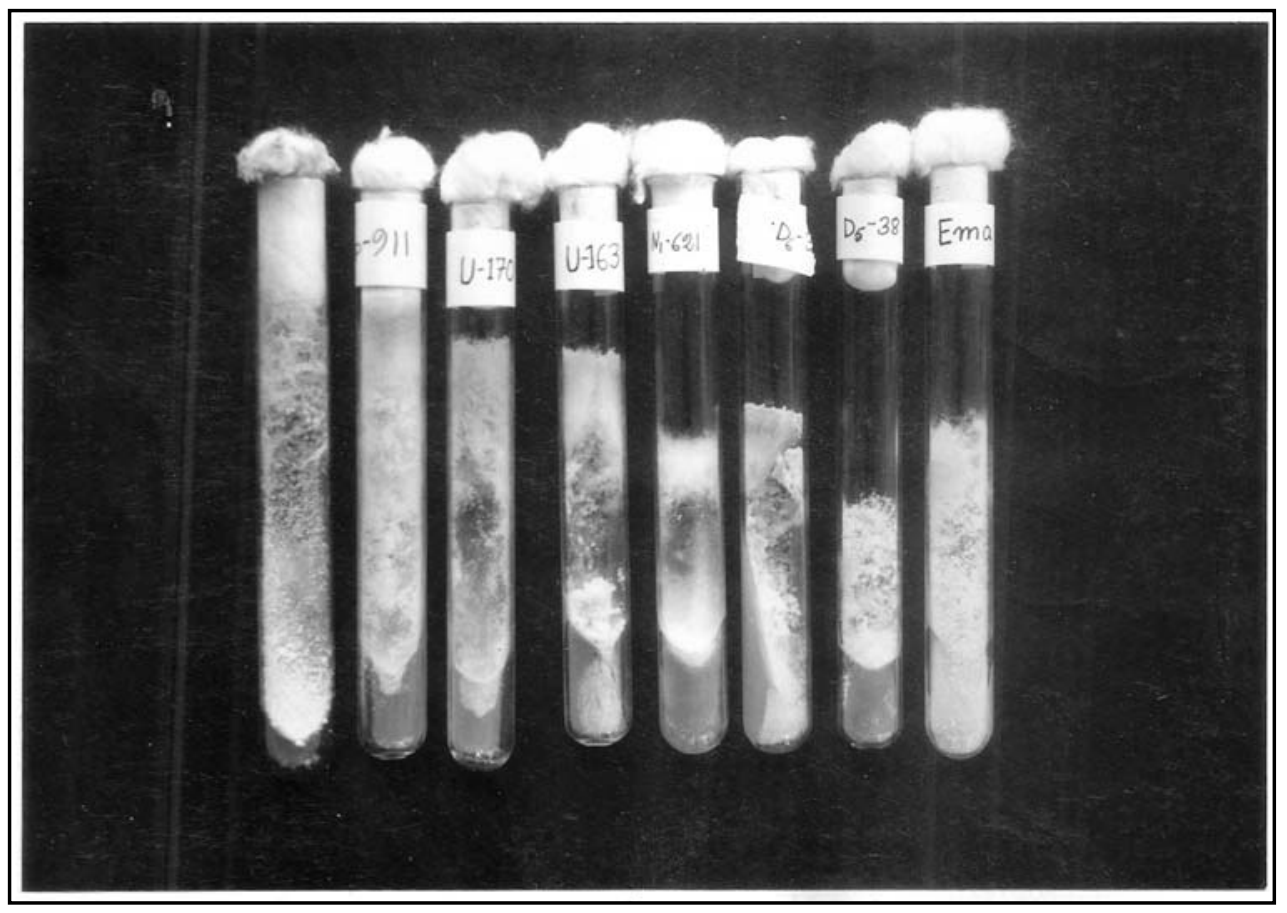

Fig. 2. plug (no labeling test tube), vigorous (U-911), dirty (U-170), buff (U-163), albino (N1621), ropy (D6-3), conidial band (D5-38) and Ema mutants 
Table I. Classification of the Neurospora crassa mutants

\begin{tabular}{|c|c|c|}
\hline $\begin{array}{l}\text { Name of } \\
\text { the mutant }\end{array}$ & Characteristics of the mutants & $\begin{array}{l}\text { Aqueous extracts } \\
\text { of Kalomegh }\end{array}$ \\
\hline Ropy & $\begin{array}{l}\text { The mycelia look like beautiful ropes, conidia pinkish } \\
\text { orange in colour. Growth is less than wild type }\end{array}$ & $100 \%$ extracts. \\
\hline Albino & $\begin{array}{l}\text { Less growth of mycelia, conidia are very scanty in number. } \\
\text { Mycelia and conidia are completely colourless. }\end{array}$ & $100 \%$ extracts. \\
\hline dirty & Small conidial lump scattered here and there in the tube. & $100 \%$ extracts. \\
\hline buff & $\begin{array}{l}\text { Growth checked and lie on the surface of the media. } \\
\text { Conidia buff in coloration }\end{array}$ & $100 \%$ extracts. \\
\hline plug & $\begin{array}{l}\text { The mycelial growth reach the plug of the tube, deep pink } \\
\text { conidia formed outside the tube, conidia around the plug. }\end{array}$ & $50 \%$ extracts. \\
\hline $\begin{array}{l}\text { vigorous } \\
\text { (mycelial) }\end{array}$ & $\begin{array}{l}\text { Densed mycelial growth, growth reach the plug, } \\
\text { mycelia cottony. }\end{array}$ & $50 \%$ extracts \\
\hline pigmented & Mycelia rope like, deep orange colored pigmentation & $50 \%$ extracts. \\
\hline conidial brand. & $\begin{array}{l}\text { Dense conidial growth form a band shaped structure } \\
\text { at the top. }\end{array}$ & $50 \%$ extracts. \\
\hline
\end{tabular}

\section{Acknowledgement}

The authors gratefully acknowledge the receipt of financial grant from the Ministry of science and Information and Communication Technology, People's Republic of Bangladesh for carry out the present research work.

\section{References}

Ahmed, N. and Sultana, K. (1984) Fungitoxic effect of garlic on treatment of jute seed. Bangladesh Jour. Bot. 13 : 130-136.
Altenberg, E. (1957) Genetics Oxford and IBH Publishing Co.

Anwar, M.N.; Singha, P.; Begum, J. and Chowdhury, J.U. (1994) Antifungal activities of some selected plant extracts on phytopathogenic fungi. Bangladesh Journal of Life Science. 6 : 23-26.

Bashar, M.A. and Bharat Rai. (1991) Antifungal activity of some plant extracts against Fusarium oexosporium f. sp. ciccri Bangladesh J. Bot. 20 (2) : 219-222. 
Beadle, G.W. and Tatum, E.L. (1941) Genetic control of biochemical reactions in Neurospora Proc. Natl. Acad. Sci., U.S.A. 27: 499-506.

Catcheside, D.G. (1949) Isolation of Nutritional Of Nutritional mutants of N. crassa by filtration enrichment. Gen. Microbiol. 11 : 34.

Fincham , J.R.S. and Day, P.R. (1965) Fungal genetics, 2nd ed., Blackwell Scientific Publications, Oxford.

Fishbein, L.W.; Flarnm, G. and Falk, H.L. (1970) Chemical mutagens. Acad. Press. New York.

Gardner, E.J. (1972) Principles of Genetics, 4th Ed., Wiley Eastern Private Ltd., New Delhi.

Haque, T. and Shamsi, S. (1996) Activity of certain plant extracts against jute stem rot fungus Macrophomina phaseolina Dhaka Univ. J. Biol. Sci 5(1) : 103-104.
Horowitz, N.H. (1973) Neurospora crassa and the beginning of molecular genetics Neurospora Newsl. 20 : 4-6.

Kolmark, G. and Westergaards, M. (1949) Induced back mutation in a" specific gene of $N$. crassa. Hereditus 35 : 490-506.

Miah, M. A.; Ahmad, T.; Sharma, H.U.; Ali, N.R. and Miah, S. A. (1990) Antifungal activities of some plant extracts. Bangladesh $J$. Bot. 19 : 5-10.

Ryan, F.J.; Beadle, G.W. and Tatum, E.L. (1943) The tube method of measuring the growth rate of Neurospora crassa. Am. J. Bot. 30 : 784-799.

Sternberg, L.; Louse Glass and Tony Griffiths (1939) Isolation and sequences analysis of a novel a mutant that confers fertility and heterokaryon compatibility in Neurospora crassa Fungal Genet. Newslett. 40A: 58.

Vogel, J.J. (1956) A convenient growth medium for Neurospora, Microb. Genet. Bull 13 : 42-43.

Received : April 02, 2007

Accepted : -------, 2007 